
\title{
25 Research Soure \\ Longitudinal borehole functionality in 15 rural Ghanaian towns from three groundwater quality clusters
}

\section{Olivia L. Schultes}

University of Washington School of Public Health

\section{Mustafa Sikder}

IHME: Institute for Health Metrics and Evaluation

\section{Emmanuel A. Agyapong}

University College of Agriculture and Environmental Science

\section{Michelle O. Sodipo}

Harvard University T H Chan School of Public Health

\section{Elena N. Naumova}

Tufts University Friedman School of Nutrition Science and Policy

\section{Karen C. Kosinski}

Tufts University School of Arts and Sciences

\section{Alexandra Kulinkina ( $\nabla$ akulinkina@gmail.com ) \\ Tufts University Friedman School of Nutrition Science and Policy https://orcid.org/0000-0002-4777- 1254}

\section{Research Article}

Keywords: Boreholes, Functionality, Water quality, Distance, Payment, Ghana

Posted Date: February 23rd, 2022

DOI: https://doi.org/10.21203/rs.3.rs-1253310/v1

License: (c) (1) This work is licensed under a Creative Commons Attribution 4.0 International License. Read Full License

Version of Record: A version of this preprint was published at BMC Research Notes on March 22nd, 2022. See the published version at https://doi.org/10.1186/s13104-022-05998-1. 


\section{Abstract}

Objective: In sub-Saharan Africa, $45 \%$ of the rural population uses boreholes (BHs). Despite recent gains in improved water access and coverage, parallel use of unimproved sources persists. Periodic infrastructure disrepair contributes to non-exclusive use of BHs. Our study describes functionality of BHs in 2014, 2015, and 2016 in 15 rural towns in the Eastern Region of Ghana sourced from three groundwater quality clusters (high iron, high salinity, and control). We also assess factors affecting crosssectional and longitudinal functionality using logistic regression.

Results: $\mathrm{BH}$ functionality rates ranged between $81 \%$ and $87 \%$ and were similar across groundwater quality clusters. Of $51 \mathrm{BHs}$ assessed in all three years, 34 (67\%) were consistently functional and only 3 (6\%) were consistently broken. There was a shift toward proactive payment for water over the course of the study in all but the high iron cluster. Payment mechanism, population served, presence of nearby alternative water sources, and groundwater quality cluster were not significant predictors of crosssectional or longitudinal $\mathrm{BH}$ functionality. However, even in the high iron cluster, where water quality is poor and no structured payment mechanism for water exists, BHs are maintained, showing that they are important community resources.

\section{Introduction}

In sub-Saharan Africa, 59\% of the population lives in rural areas [1] and $45 \%$ is estimated to use boreholes (BHs) [2]. In Ghana, according to the 2014 Demographic and Health Survey, $45 \%$ of rural residents reported using a $\mathrm{BH}$ as their primary source of drinking water, while $20 \%$ primarily used unimproved sources, such as unprotected hand-dug wells, unprotected springs, or surface water [3]. Despite recent gains in improved water access and coverage, parallel use of improved and unimproved sources persists in rural Ghana [3-5]. Periodic infrastructure disrepair contributes to non-exclusive use of $\mathrm{BHs}$; at any given time, approximately $26 \%$ of $\mathrm{BHs}$ in Ghana are broken [6].

Predictors of $\mathrm{BH}$ functionality have been evaluated using primarily cross-sectional studies. Improved functionality has been associated with access to pump spare parts and skilled labor [7-8], presence of a payment scheme [7-8], and external post-construction support programs [5]. Reduced functionality was associated with $\mathrm{BH}$ installation during the rainy season [9], infrastructure age [7], and longer distances to a major city [8]. The presence and number of alternative water sources in a community has also been negatively associated with $\mathrm{BH}$ functionality $[5,7]$.

Although inherently a dynamic concept, a relatively small number of studies have attempted to capture $\mathrm{BH}$ functionality over time, primarily through retrospective key informant interviews [7-8, 10-12]. Qualitative information on historical functionality was used in conjunction with a single observed functionality measure. The substantial lack of longitudinal BH functionality data in low-income countries is partly due to fragmented systems for $\mathrm{BH}$ construction and monitoring and the resource-intensive nature of repeated field observations [13-14]. 
The present study describes longitudinal functionality of BHs over the course of three years in 15 rural Ghanaian towns. We use logistic regression to explore common factors affecting functionality, such as payment mechanism, population served, presence of alternative water sources, and groundwater quality. The primary contributions of the study are the longitudinal quantitative functionality data and contextual knowledge from three years of monitoring.

\section{Methods}

\section{Study setting}

We conducted several prior studies in the Eastern Region of Ghana investigating water infrastructure. The first study showed that groundwater access in the area is abundant, with $87-95 \%$ of the population having access to a borehole within 500 meters. Despite this, surface water continues to be used extensively [15]. The second study identified three distinct spatial groundwater quality clusters: high iron, high salinity, and a control area with no detected water quality problems [16]. Our third study showed that households in the high iron and high salinity clusters were significantly more likely to use surface water as compared to the control cluster [4]. This study investigated $\mathrm{BH}$ functionality over three years in the same 15 towns as the water use study [4], distributed among the three groundwater quality clusters. The towns ranged in population between 829 and 3,347 people and relied on a combination of BHs, hand-dug wells and surface water.

\section{Data collection}

We collected several types of data about public water sources in January 2014, May 2015, and May 2016 (Table 1). The geographic locations of features were recorded using a handheld GPS device (Garmin GPS 165 72H Portable Navigator, Garmin, Ltd.) or the iPad GPS Tracks app (version 2.8.7). BH functionality was determined by manually testing each $\mathrm{BH}$ to see if it produced water. Functionality status was also ascertained with nearby residents. BH water quality was tested in 2015 by a certified water quality laboratory [16]. BH payment method was collected using an open-ended question, triangulated between nearby residents and the water committee members, and subsequently categorized.

\section{Data analysis}

We derived several analysis variables from the available data (Table 1). Groundwater quality clusters were allocated based on spatial interpolation of water quality results, namely iron and total dissolved solids concentrations [16]. Reported payment methods fell into one of three categories: proactive (per volume or unit of time), reactive (per household once the $\mathrm{BH}$ is already broken), or no payment. Reactive and no payment were combined to form a binary payment variable (Table 1). A service area was delineated as a 300-meter Euclidean buffer distance around each BH. Population served was calculated as the number of households within the buffer area (mapped in 2016), multiplied by the average 
household size of 3.5 [3], and categorized (Table 1). Lastly, we created a binary variable for whether there was another water source (e.g., another $\mathrm{BH}$, hand-dug well or surface water source) available within the $300 \mathrm{~m}$ buffer distance of each $\mathrm{BH}$. All geospatial analyses were conducted in ArcGIS software (version 10.5.1).

We applied univariable and multivariable logistic regression models to assess the association between $\mathrm{BH}$ functionality and the four explanatory variables in each of the three study years. A fourth model used the same explanatory variables on a dataset of $\mathrm{BHs}$ that were examined in all three time points. For this analysis, longitudinal functionality status was defined as $1 \mathrm{for}$ BHs that were functional at all three time points and 0 for $\mathrm{BHs}$ that were non-functional at least once.

Table 1: Summary of data collected in 2014, 2015, and 2016 and analysis variables

\begin{tabular}{lllc} 
Data collected & 2014 & 2015 & 2016 \\
\hline Borehole GPS coordinates & $\square$ & $\square$ & $\square$ \\
\hline $\begin{array}{l}\text { Hand-dug well GPS } \\
\text { coordinates }\end{array}$ & $\square$ & $\square$ \\
\hline $\begin{array}{l}\text { Surface water access point } \\
\text { GPS coordinates }\end{array}$ & $\square$ & $\square$
\end{tabular}

Household GPS coordinates

प

Borehole functionality

(

]

प

Borehole water quality

प

Borehole payment method

(

प

Analysis Type Definition

variable

Functionality Binary $\quad 1=$ functional; $0=$ not functional status

Groundwater Categorical control = no identified water quality problems; high salinity = quality cluster elevated total dissolved solids concentration; high iron = elevated iron concentration

Payment
mechanism Binary $\quad 1=$ proactive; $0=$ reactive or none

Population Binary $\quad 1=600+$ people; $0=\leq 600$ people

served within

$300 \mathrm{~m}$

Another water Binary $\quad 1=$ present; $0=$ absent

source within

$300 \mathrm{~m}$ 


\section{Results}

Over the course of the study, we identified a total of 63,67 , and 73 BHs in the 15 towns in 2014, 2015, and 2016 , respectively. Of these, $81 \%, 87 \%$ and $81 \%$ were functional in each year. Functionality rates were similar across the water quality clusters, but some towns (e.g., towns $4,5,10,12$ ) had notably lower functionality rates than others (Figure 1). In 2014, most towns had a reactive or no payment mechanism for water (3/5 in the control and high salinity clusters and 5/5 in the high iron cluster). Between 2014 and 2016, four towns switched to a proactive payment mechanism ( 1 in control, 2 in high salinity and 1 in high iron). In 2016, most towns had a proactive payment mechanism, with reactive payment predominating only in the high iron cluster ( $4 / 5$ towns). The average number of people per $\mathrm{BH}$ ranged between 272 and 1,200 (sd = 447) across study towns, with slightly higher numbers in the control cluster $(p>0.05)$.

A total of $51 \mathrm{BHs}$ were present in all three datasets and used for assessing longitudinal functionality. Of these, 34 (67\%) were functional during all three time points, 11 (21\%) were broken during one time point, 3 $(6 \%)$ were broken during two time points, and $3(6 \%)$ were broken during all three time points. We tested each of the four explanatory variables to assess associations with cross-sectional and longitudinal $\mathrm{BH}$ functionality using univariable logistic regression (Table 2). None of the variables were significant predictors of BH functionality in any of the models. Multivariable logistic regression produced similar results (not shown), none of which were statistically significant. Payment mechanism and presence of another water source within $300 \mathrm{~m}$ were not evaluated in 2015 because they were not assessed in the field (Table 1).

Table 2

Odds ratios and $95 \%$ confidence intervals from univariable logistic regression models.

\begin{tabular}{|lllll|}
\hline & 2014 & 2015 & 2016 & Longitudinal \\
\hline & $\mathrm{n}=63$ & $\mathrm{n}=67$ & $\mathrm{n}=73$ & $\mathrm{n}=51$ \\
\hline Water quality cluster: high salinity & $1.7(0.3,11.1)$ & $0.9(0.1,6.5)$ & $0.4(0.1,2.2)$ & $1.1(0.2,6.0)$ \\
\hline Water quality cluster: high iron & $1.0(0.3,4.2)$ & $1.1(0.2,5.3)$ & $0.6(0.1,2.6)$ & $0.8(0.2,3.1)$ \\
\hline Payment mechanism: proactive & $1.0(0.2,4.4)$ & - & $3.4(0.4,30.1)$ & $0.8(0.2,2.6)$ \\
\hline Population served: $>$ 600 & $0.2(0.0,1.7)$ & $0.7(0.1,3.7)$ & $1.1(0.3,3.9)$ & $0.6(0.2,2.1)$ \\
\hline Another water source: present & $0.7(0.1,6.3)$ & - & $0.8(0.1,7.7)$ & $0.8(0.2,2.6)$ \\
\hline
\end{tabular}

\section{Discussion}

We present the results of three years of $\mathrm{BH}$ functionality monitoring. We hypothesized that groundwater quality, and therefore the level of satisfaction with $\mathrm{BH}$ water quality, would have a bearing on functionality. However, we found that in any given year, approximately $20 \%$ of the BHs were broken in the 
study towns, with no differences across clusters. This is consistent with other studies conducted in rural Ghana [6-7]. In a complementary study conducted in the same 15 towns, we found that groundwater quality also did not reduce self-reported $\mathrm{BH}$ use, but rather increased the use of other water sources such as hand-dug wells and surface water [4]. However, this finding was based only on categorical selfreported use and not on the relatively volume of water used from each source.

Here, we found that $67 \%$ of the BHs observed at all three time points were consistently functional and only three BHs were consistently broken (one in each water quality cluster), showing a concerted effort to finance and repair BHs over time. We also found that some study towns switched from not paying for water at all or paying reactively when a $\mathrm{BH}$ breaks to a proactive payment mechanism over the course of the monitoring period. This shift was more common in the control and high salinity clusters. In the high iron cluster, four of five towns still were not charging for $\mathrm{BH}$ water in 2016. This is consistent with the contextual knowledge of our study team: residents of towns with elevated iron content are generally unwilling to pay for $\mathrm{BH}$ water and prefer to use free alternative water sources widely available in their neighborhoods.

We also observed that the number of water users per $\mathrm{BH}$ was higher in the control cluster, as compared to towns with water quality problems. This observation is also consistent with the overall higher number of BHs in towns with water quality problems. In the case of the high iron cluster, iron concentrations in the water samples are more than ten times higher (up to $4.5 \mathrm{mg} / \mathrm{L}$ ) than the water quality standard in Ghana $(0.3 \mathrm{mg} / \mathrm{L})$ [16]. We suspect that while BHs are being constructed, and water testing results reflect unsatisfactory quality, more BHs may be drilled to find a depth or location with lower iron levels. This may result in a higher number of $\mathrm{BHs}$ in these locations as compared to places where water quality standards are met.

We note that we intentionally excluded some important predictors that were significant in other studies: namely, presence of a water committee and the availability of and distance to $\mathrm{BH}$ mechanics and spare parts $[12,17]$. Presence of a water committee was excluded because it was highly correlated with proactive payment mechanism. Distance to $\mathrm{BH}$ mechanics and spare parts was excluded because all towns were located relatively close $(<25 \mathrm{~km})$ to district capitals that had these resources, exhibiting no variability in the dataset.

Historically, government resources in sub-Saharan African countries have been insufficient to repeat large-scale data collection efforts and track infrastructure over time [14]. More recently, there is a shift toward mapping and monitoring of existing water supplies. For example, Liberia conducted extensive water point mapping in 2011 and 2017 (https://wash-liberia.org/raw-water-point-data/). The expansion of digital technologies may provide further opportunity for cost-effective near real-time monitoring of water sources in remote and rural areas. Further availability of longitudinal data, new standardized datasharing platforms, such as the Water Point Data Exchange (https://www.waterpointdata.org/), and advances in analytical methods [18] will allow governments, funding agencies, and implementing 
organizations to study infrastructure functionality and its correlates and direct resources toward sustainability.

\section{Conclusion}

In our longitudinal dataset, payment method, population served, and presence of an alternative water source were not associated with $\mathrm{BH}$ functionality. Although organoleptic groundwater quality changed the water use patterns of the study communities [4], it did not affect $\mathrm{BH}$ functionality status over the three-year monitoring period. Interestingly, in the high iron cluster, despite poor groundwater quality and lack of regular payment for water, the towns managed to maintain and repair their BHs, showing that they are important community resources. While we had collected the data several years ago, the research related to sustainability of most common water sources in low-resource settings remains limited. In combination with our prior studies, this dataset contributes to generating future hypotheses regarding the dynamic relationships between groundwater quality, functionality, utilization, and financial sustainability of rural water resources.

\section{Limitations}

- The number of BHs sampled and the number of explanatory variables are relatively small, which may have led to null findings and limited generalizability.

- The length of the monitoring period was also short. More data points over a longer follow-up period would have enabled a more interesting longitudinal analysis using methods such as time series or survival analysis.

\section{Abbreviations}

BH: Borehole; GPS: Global Positioning System.

\section{Declarations}

\section{Acknowledgments}

We thank Gilbert A. Ayamgah and Theophilus Mensah (Community Water and Sanitation Agency) for approving the study and providing logistical support, town leaders for allowing access to the study communities, and community water committees to be interviewed.

\section{Author's contributions}

AVK, KCK and OLS designed the study; OLS, MOS and EAA collected the data; OLS, KCK, MS and AVK analyzed the data; OLS, KCK and AVK drafted the manuscript; ENN provided analytical and structural guidance. All authors have read, made substantive edits, and approved the manuscript. 


\section{Funding}

This study was funded in part by the Tufts Institute for Innovation and National Institutes of Health (R34 Al097083-01A1).

\section{Availability of data}

The data are available from the corresponding author upon request.

\section{Ethics approval and consent to participate}

This study utilized secondary data about infrastructure attributes from prior studies. It did not require ethics approval.

\section{Consent for publication}

Not applicable.

\section{Competing interests}

The authors declare no competing interests.

\section{References}

1. The World Bank, 2020. Data Catalog. (Accessed on 28 December 2021) https://data.worldbank.org/indicator/SP.RUR.TOTL.ZS?locations=ZG

2. Handpump Data, 2009. Selected Countries in Sub-Saharan Africa: Sustainable Rural Water Supplies, Online Database Collated by Peter Harvey, UNICEF Zambia; Rural Water Supply Network: St. Gallen, Switzerland. http://www.rural-water-supply.net/_ressources/documents/default/203.pdf.

3. Ghana Statistical Service (GSS), Ghana Health Service (GHS), and ICF International, 2015. Ghana Demographic and Health Survey 2014, Rockville, Maryland, USA. https://dhsprogram.com/pubs/pdf/FR307/FR307.pdf.

4. Kulinkina AV, Sodipo MO, Schultes OL, Osei BG, Agyapong AA, Egorov Al, et al., 2020. Rural Ghanaian households are more likely to use alternative unimproved water sources when water from boreholes has undesirable organoleptic characteristics. Int J Hyg Environ Health 227: 113514.

5. Whittington D, Davis J, Prokopy L, Komives K, Thornsten R, Lukacs H, et al., 2009. How well is the demand-driven, community management model for rural water supply systems doing? Evidence 
from Bolivia, Peru and Ghana. Water Policy 11: 696-718.

6. Foster T, Furey S, Banks B, Willetts J, 2020. Functionality of handpump water supplies: a review of data from sub-Saharan Africa and Asia-Pacific region. Int J Water Resour Dev 36 (5): 855-869.

7. Fisher MB, Shields KF, Chan TU, Christenson E, Cronk RD, Leker H, et al., 2015. Understanding handpump sustainability: determinants of rural source functionality in the Greater Afram Plains region of Ghana. Water Resour. Res. 51: 8431-8449.

8. Foster T, 2013. Predictors of sustainability for community-managed handpumps in sub-Saharan Africa: evidence from Liberia, Sierra Leone, and Uganda. Environ. Sci. Technol. 47: 12037-12046.

9. Harvey P, 2004. Borehole sustainability in rural Africa: an analysis of routine field data. In: Godfrey, S. (ed). People-centred approaches to water and environmental sanitation: Proceedings of the 30th WEDC International Conference, Vientiane, Laos, 25-29 October 2004, p. 339-346.

10. Alexander KT, Tesfaye Y, Dreibelbis R, Abaire B, Freeman MC, 2015. Governance and Functionality of Community Water Schemes in Rural Ethiopia. Int J Public Health 60: 977-986.

11. Kativhu T, Mazvimavi D, Tevera D, Nhapi I, 2017. Factors influencing sustainability of communallymanaged water facilities in rural areas of Zimbabwe. Phys Chem Earth 100: 247-257.

12. Kativhu T, Madzivanyika TT, Nunu WN, Macherera M, Chinyama A, 2021. Sustainability of water facilities under community based management in Zimbabwe. Journal of Water Supply: Research and Technology - Aqua: jws2021089.

13. Yu W, Wardrop NA, Bain RES, Wright JA, 2017. Integration of population census and water point mapping data - A case study of Cambodia, Liberia and Tanzania. Int J Hyg Environ Health 220: 888-899.

14. Whaley L, Cleaver F, Mwathunga E, 2021. Flesh and bones: Working with the grain to improve community management of water. World Development 138: 105286.

15. Kulinkina AV, Kosinski KC, Plummer JD, Durant JL, Bosompem KM, Adjei MN, et al., 2017. Indicators of improved water access in the context of schistosomiasis transmission in rural Eastern Region, Ghana. Sci. Total Environ. 579, 1745-1755.

16. Kulinkina AV, Plummer JD, Chui KKH, Kosinski KC, Adomako-Adjei T, Egorov Al, et al., 2017. Physicochemical parameters affecting the perception of borehole water quality in Ghana. Int J Hyg Environ Health 220, 990-997.

17. Foster T, Willetts J, Lane M, Thomson P, Katuva J, Hope R, 2018. Risk factors associated with rural water supply failure: A 30-year retrospective study of handpumps on the south coast of Kenya. Sci. Total Environ. 626: 156-164.

18. Yu W, Wardrop NA, Bain RES, Alegana V, Graham LJ, Wright JA, 2019. Mapping access to domestic water supplies from incomplete data in developing countries: An illustrative assessment for Kenya. PLoS ONE 14(5): e0216923.

\section{Figures}



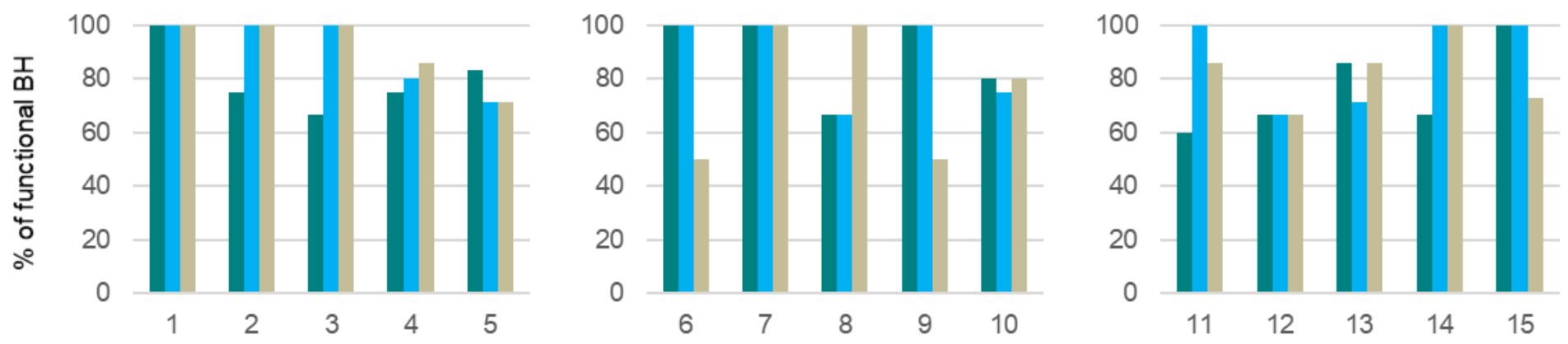

\section{Figure 1}

Borehole functionality (\%) across study towns in control [towns 1-5 on the left], high salinity [towns 6-10 in the center], and high iron [towns 11-15 on the right] water quality clusters. Three bars for each town represent years $(2014,2015$, and 2016$)$ from left to right. 